\title{
Diffusion of Electrolytes in Hydrolyzable Glassy Polymers: Acetic Acid in Poly(vinyl acetate), Poly(vinyl alcohol), and Polyesters
}

\author{
A. YA. POLISHCHUK, ${ }^{1}$ A. J. M. VALENTE, $^{2}$ G. CAMINO, $^{3}$ M. P. LUDA, ${ }^{3}$ N. N. MADYUSKIN, ${ }^{1}$ V. M. M. LOBO, ${ }^{2}$ \\ G. E. ZAIKOV, ${ }^{1}$ M. REVELLINO ${ }^{4}$ \\ ${ }^{1}$ Institute of Biochemical Physics, Russian Academy of Sciences, 4 Kosygin Street, Moscow 117334, Russia \\ 2 Department of Chemistry, University of Coimbra, 3004-535 Coimbra, Portugal \\ ${ }^{3}$ Department of Inorganic, Physical and Material Chemistry, University of Turin, Via P. Giuria, 10125 Torino, Italy \\ ${ }^{4}$ IVECO S.p.A., Lungo Stura Lazio 35, 10153 Torino, Italy
}

Received 29 August 2000; accepted 19 December 2000

\begin{abstract}
Engineering materials containing poly(vinyl acetate) (PVAc) as the key component undergo hydrolytic degradation, which must be minimized or, at least, controlled. To characterize PVAc hydrolysis quantitatively, the diffusion of acetic acid (HAc) in PVAc, poly(vinyl alcohol) (PVA), unsaturated polyester (UPE), and a UPE/ PVAc blend was studied in detail. The permeability cell earlier developed by the authors was modified here to reduce experimental error. As the diffusion and solubility coefficients of water and HAc in the above materials were measured at different temperatures, a mathematical model was developed, which takes proper account of the combined water and HAc diffusion in PVAc undergoing partial hydrolysis. The model was further validated by the experimental data obtained at $70^{\circ} \mathrm{C}$ for UPE/PVAc film, simulating a matrix of sheet-molding compounds composite materials. (C) 2002 John Wiley \& Sons, Inc. J Appl Polym Sci 83: 1157-1166, 2002
\end{abstract}

Key words: acetic acid; PVAc hydrolysis; diffusion; aging; hydrophilic polymers; polyesters; composites

\section{INTRODUCTION}

Diffusion of electrolytes takes place in synthetic and natural polymeric materials when they are exposed to the environment, that is, nearly in all their applications. ${ }^{1}$ The understanding of the role of diffusion in the process of modification and degradation of polymers is, therefore, necessary in light of their commercial application. ${ }^{1,2}$ Such

Correspondence to: G. E. Zaikov (chembio@sky.chph. ras.ru). Journal of Applied Polymer Science, Vol. 83, 1157-1166 (2002)

() 2002 John Wiley \& Sons, Inc.

DOI 10.1002/app.10163 an example is sheet molding compounds (SMCs), the polymeric composites derived from unsaturated polyester resin reinforced with glass fibers. These materials are widely applied in automotive, aviation, and other industries. ${ }^{2}$

SMC formulations based on polyester resins undergo from 7 to $8 \%$ volume shrinkage when cured and are only partially compensated by the solid phases (fillers, fibers) incorporated into the matrix. To compensate shrinkage to an extent depending on their nature, some thermoplastic polymers are introduced into SMCs. The best results are achieved with poly(vinyl acetate) (PVAc), which completely suppresses the shrinkage [e.g., poly(methyl methac- 
rylate) and polystyrene reduce the linear shrinkage to 0.05 and $0.2 \%$, respectively]. ${ }^{3,4}$

On the other hand, once PVAc-containing material is exposed to the environment, water interaction with PVAc results in the formation of acetic acid (HAc) and poly(vinyl alcohol) (PVA). HAc further provokes decomposition of the main filler, calcium carbonate, and a partial dissolution of glass fibers. ${ }^{5}$ At the same time, PVA, being highly hydrophilic, favors the physical processes leading to substantial material hydrophilization, which occurs when water penetrates into the composites. In PVAc-containing polyester resin-glass fiber composites, these processes are the swelling and partial dissolution of vinyl acetate and vinyl alcohol sequences and unsaturated polyester (UPE) plasticization. Therefore, PVAc hydrolysis, which promotes the softening of the SMC composites and consequent loss of their mechanical properties, may prevent the use of PVAc owing to its effect on the durability in spite of its superior performance in terms of shrinkage control. ${ }^{6,7}$

The main scope of this article was to measure the parameters required for a quantitative description of chemical modifications of processes that occurred in PVAc-containing engineering materials. Thus, we improved a tool earlier developed to predict the durability of PVAc-containing materials at different environmental conditions.

On the other hand, information about electrolyte diffusion is not limited by the investigation of hydrolytic degradation of linear polymers and the prediction of their effective lifetime. It has also proved helpful toward gaining a deeper insight into the processes of biological degradation of polymers with applications in medicine, for example, (as in the case of PVAc) in design of drugdelivery devices. ${ }^{1,8}$

\section{EXPERIMENTAL}

\section{Materials and Chemicals}

The following materials were received from commercial sources:

- PVAc in a $40 \%$ styrene solution $\left(M_{w}\right.$ = 90,000);

- Sixty-five percent styrene solution of unsaturated polyester (UPE: $M_{w}=10,000$ ) obtained by polycondensation of maleic anhydride with ethyl and butyl glycols;

- PVA $\left(M_{w}=120,000\right)$ in powder.

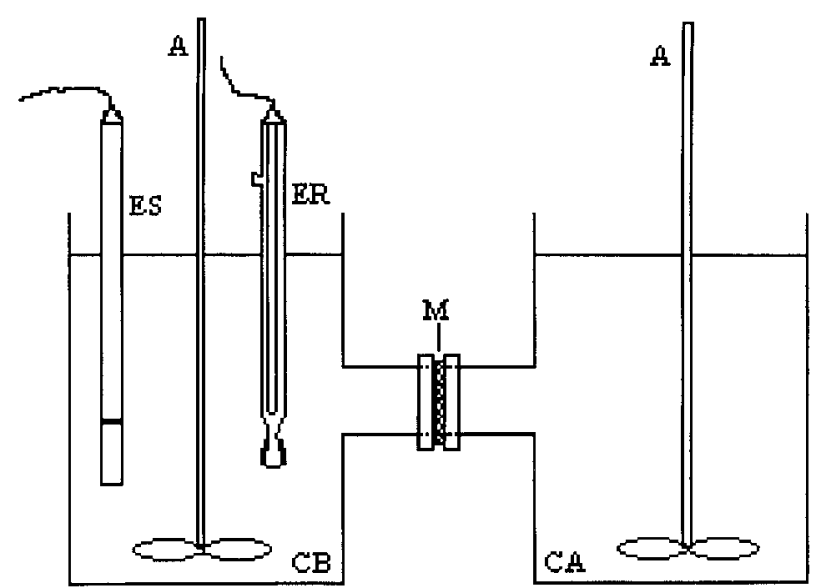

Figure 1 Permeability cell. CA, compartment A; CB, compartment B; M, membrane; A, stirrer; ER, reference electrode; ES, selective electrode.

A UPE/PVAc blend was prepared by mixing the above solutions in a weight-to-weight ratio of $3 / 2$, yielding a weight-to-weight UPE/PVAc ratio of $2.44 / 1$, similar to that in SMC composites. PVA powder was dissolved in water at $70^{\circ} \mathrm{C}$ prior to membrane preparation.

The solution of each single material (PVAc, UPE, and PVA) was deposited on a glass sheet and spread out using an apparatus providing a membrane of a uniform thickness (approximately $0.33 \mathrm{~mm}$ ). As the solvent evaporated completely at ambient temperature, the membrane was removed from the glass sheet using water. ${ }^{9}$ Slices of the UPE/PVAc blend of the same thickness ( 0.33 $\mathrm{mm}$ ) were obtained by pouring the corresponding viscous styrene solutions between two parallel glass slabs and curing for $2 \mathrm{~h}$ at $100^{\circ} \mathrm{C}$. HAc aqueous solutions covering the range $0.1-1 M$ were obtained by step-by-step dissolution of $99 \%$ glass acetic acid received from Merck (Wien, Austria).

\section{Methods}

\section{Permeability Measurements}

HAc permeability through polymeric membranes was measured using two cells of $250 \mathrm{~mL}$ each connected by two horizontal tubes of a $7-\mathrm{mm}$ radius (Fig. 1). The polymeric membrane was sealed, with silicone, between these two tubes, thus providing proper conditions for application of the so-called time-lag method described in the literature. ${ }^{9,10}$ Control experiments were performed to ensure that there is no silicone in the permeation area as well as that mass transport 
occurs on the polymer-solution interface only. To prevent any contribution of the hydrostatic pressure $^{11}$ to the acid flux, one cell (compartment A) was filled with $180 \mathrm{~mL}$ of HAc, whereas $170 \mathrm{~mL}$ of water were used in the other cell (compartment B). The membranes were immersed in water for 1 day prior to the experiments. The thickness of the membrane was measured after each experiment using a Helias micrometer with a resolution of 0.1 $\mathrm{mm}$. The HAc concentration in the cell, initially filled with water, was calculated from the permeability experiments by measuring the conductivity using an YSI 3200 instrument. The conductivity equipment was calibrated (i.e., the dependence of conductivity on the HAc concentration in an aqueous solution was measured) prior to each experiment using fresh standard HAc solutions (solutions of at least five different concentrations) with a concentration range within one order of magnitude. The conditions of calibration and consequent permeability experiments were the same. The temperature remained constant throughout the permeability experiments (Multistirrer 6 thermostatic bath from Velp Scientifica). Solutions in both cells were stirred at about $200 \mathrm{rpm}$ with magnetic stirrers to decrease the Nernst layer in the membrane-solution interface as well as to increase the reproducibility of the sensor for the conductivity instrument. The data were read during the first $10 \mathrm{~h}$ for each experiment, which is the time sufficient to secure a steady-state flux of acid. The diffusion coefficients of HAc were measured in permeability experiments for 20 and $40^{\circ} \mathrm{C}$ and then extrapolated to higher temperatures up to $70^{\circ} \mathrm{C}$ using the Arrhenius approximation.

\section{Sorption/Desorption Experiments}

In the case of UPE/PVAc, the methodology of the experiments, on combined sorption of water and desorption of HAc, included the following steps:

- Sorption experiments were performed isothermally at $70^{\circ} \mathrm{C}$ in "hydrothermal" conditions (sorption from liquid water) ${ }^{5-7,12}$ on films conditioned in an exsiccator under a vacuum to a constant weight $\left(W_{i}\right)$ at the temperature of the next experiment.

- Using a Sartorius analytical balance, with a resolution of $0.1 \mathrm{mg}$, a film was weighed $\left(W_{t}\right)$ at selected times $(t)$ after wiping the drops of water. Then, water was desorbed by heating at the temperature of the corresponding sorption experiment under a vacuum to a constant weight $\left(W_{0}\right)$. The results of the water-desorption experiments were further treated to calculate the water-diffusion coefficient corresponding to the time $(t)$ of sorption (see below).

- The weight $\left(M_{\mathrm{wt}}\right)$ of water and its concentration in the material $\left(C_{\mathrm{wt}}: \mathrm{g} / \mathrm{g}\right)$ were calculated from

$$
M_{\mathrm{wt}}=W_{t}-W_{0} ; C_{\mathrm{wt}}=M_{\mathrm{wt}} / W_{t}
$$

- Sorption experiments were completed when $C_{\mathrm{wt}}$ became constant, $C_{w \infty}$ ("equilibrium value").

- The water-diffusion coefficient of specimens undergoing water sorption was calculated from the desorption experiments which were proved $^{5-7,12}$ to show Fickian kinetics:

$$
C_{\mathrm{wt}}^{d} / C_{w 0}=1-4\left(D_{w} t / \pi l^{2}\right)^{1 / 2}
$$

where $C_{\mathrm{wt}}^{d}$ is the water concentration in the material as it varies with time during the desorption process, and $C_{w 0}$, the water concentration in the material prior to desorption: It corresponds to the concentration of water absorbed by the material before desorption begins.

- The amount of acid $\left(M_{\mathrm{st}}\right)$ leached the material to time $t$ was calculated from

$$
M_{\mathrm{st}}=W_{i}-W_{0}
$$

- Similar to the water case, leaching experiments were completed when $M_{\text {st }}$ became a constant equilibrium value, $M_{s \infty}$.

The experimental error for the weight measurements is $2-3 \%$ as earlier evaluated for similar experiments. $^{7}$

\section{Data Treatment}

The methodology of the data treatment is based on a model which takes into account chemical and physical interactions between diffusing water and the material. ${ }^{5-7}$ At this stage, a simplified version of this model was used which describes water sorption and formation and leaching of HAc by the equations

$$
\begin{aligned}
\partial C_{w} / \partial t=(\partial / \partial x)\left(D_{w} \partial C_{w} / \partial x\right) & \\
-k C_{w}\left(\left[P_{0}\right]-C_{w}\right) & 0<x<1 \\
\partial C_{s} / \partial t=(\partial / \partial x)\left(D_{s} \partial C_{s} / \partial x\right) & \\
+k C_{w}\left(\left[P_{0}\right]-C_{w}\right) & 0<x<1
\end{aligned}
$$




$$
\begin{aligned}
& \text { if }\left[P_{0}\right]>C_{w} \text { or } \\
& \begin{aligned}
\partial C_{w} / \partial t=(\partial / \partial x)\left(D_{w} \partial C_{w} / \partial x\right) & 0<x<1 \\
\partial C_{s} / \partial t=(\partial / \partial x)\left(D_{s} \partial C_{s} / \partial x\right) & 0<x<1
\end{aligned}
\end{aligned}
$$

if $\left[P_{0}\right] \leq C_{w}$ where $C_{w}$ and $C_{s}$ are the concentrations of water and of the acid in the material, respectively, both measured in kg-mol kg-1; $D_{w}$ and $D_{s}$, the diffusion coefficient of water and of the acid in the material, respectively; $k$, the rate constant of hydrolysis; $[P]$, the concentration of hydrolyzable polymer groups measured in kg-mol/ $\mathrm{kg}^{-1} ;\left[P_{0}\right]$ at $t=0$; and $M_{w}$, the molecular weight of water. The experimental goal was to measure the diffusion coefficients of water $\left(D_{w}\right)$ and of HAc $\left(D_{s}\right)$ as a function of water and acid concentrations, thus approaching the proper calculation of the rate of hydrolysis $(k)$.

HAc diffusion coefficients in PVAc, PVA, UPE, and UPE/PVAc were determined by measuring the permeability of acid protons and nondissociated molecules through films of the above materials equilibrated with water prior to the permeability experiments. In the PVAc and UPE/PVAc cases, the films were immersed in water for a time, ensuring that PVAc hydrolysis was complete. This time was measured in control experiments using sorption experiment methodology (see Methods above). Thus, using permeability methods, we could neglect the hydrolysis process.

The acid flux through the membrane $\left(D_{s} \partial C_{s} /\right.$ $\partial x)$ is, in fact, the sum of the fluxes of acid protons $\left(D_{H} \partial C_{H} / \partial x\right)$ and nondissociated molecules $\left(D_{N}\right.$ $\left.\partial C_{N} / \partial x\right)^{1,10}$ :

$$
D_{s} \partial C_{s} / \partial x=D_{H} \partial C_{H} / \partial x+D_{N} \partial C_{N} / \partial x
$$

where $C_{H}$ is the concentration of the acid protons, $C_{N}$, the concentration of the nondissociated molecules in the polymer. $D_{H}$ and $D_{N}$ are the diffusion coefficients of the protons and non-dissociated molecules, respectively.

Assuming that the dissociation process is much faster than is the acid diffusion, ${ }^{1}$ we can suppose the dissociation equilibrium at any point of the membrane: $K_{d}=C_{H} C_{A} / C_{N}=C_{H}^{2} / C_{N}$ ( $K_{d}$ is the dissociation constant, and $C_{A}$, the concentration of acetic ions equal to the concentration of protons due to the condition of electroneutrality). This results in the following expressions:

$$
C_{N}=C_{H}^{2} / K_{d}
$$

$$
\begin{gathered}
C_{s}=C_{N}+C_{H}=C_{H}^{2} / K_{d}+C_{H} \\
D_{s}\left[2\left(C_{H} / K_{d}\right) \partial C_{H} / \partial x+\partial C_{H} / \partial x\right] \\
=D_{H} \partial C_{H} / \partial x+2\left(D_{N} C_{H} / K_{d}\right) \partial C_{H} / \partial x \\
D_{s}\left[2\left(C_{H} / K_{d}\right)+1\right] \partial C_{H} / \partial x \\
=\left[D_{H}+2\left(D_{N} / K_{d}\right)\right] \partial C_{H} / \partial x
\end{gathered}
$$

Thus, the apparent diffusion coefficient of HAc, which is involved in eqs. (2) and (4), links to two measurable parameters $D_{H}$ and $D_{N}$ as

$$
D_{s}=\left(D_{H} K_{d}+2 D_{N} C_{H}\right) /\left(K_{d}+2 C_{H}\right)
$$

In treating the permeability experiments, we applied equations describing the diffusion of acid protons and nondissociated molecules:

$$
\begin{array}{ll}
\partial C_{H} / \partial t=(\partial / \partial x)\left(D_{H} \partial C_{H} / \partial x\right) & 0<x<1 \\
\partial C_{N} / \partial t=(\partial / \partial x)\left(D_{N} \partial C_{N} / \partial x\right) & 0<x<1
\end{array}
$$

with the following initial and boundary conditions:

$$
\begin{array}{r}
C_{H}(0, t)=K_{H} c_{H 0}, C_{H}(1, t)=0, \\
\text { and } C_{H}(x, 0)=C_{H l} \\
C_{N}(0, t)=K_{N} c_{N 0}, C_{N}(1, t)=0, \\
\text { and } C_{N}(x, 0)=C_{N l}
\end{array}
$$

where $l$ is the thickness of the polymeric membrane, and according to eq. (8), $c_{H 0}$, and $c_{H 0}$, are the concentrations of acid protons and nondissociated molecules, respectively, in the acid containing cell; $C_{H 1}$ and $C_{N 1}$, the concentrations of the same species in the membrane prior to the permeability measurements; and $K_{H}$ and $K_{N}$, the so-called partition coefficients of protons and nondissociated molecules. They are dimensionless constants obtained from volume ratios. $c_{H 0}$, $c_{N 0} C_{H l}$ and $C_{N 1}$ are derived from the HAc concentration in the acid-containing cell $\left(c_{s 0}\right)$ and the acid concentration in the membrane prior to permeability experiments $\left(C_{s 1}\right)$ as

$$
\begin{gathered}
c_{H 0}=K_{d}\left[-1+\left(1+4 c_{s 0} / K_{d}\right)^{1 / 2}\right] / 2 \\
c_{N 0}=K_{s} c_{s 0}+K_{d}\left[1-\left(1+4 c_{s 0} / K_{d}\right)^{1 / 2}\right] / 2
\end{gathered}
$$




$$
\begin{gathered}
C_{H 1}=K_{d}\left[-1+\left(1+4 C_{s 1} / K_{d}\right)^{1 / 2}\right] / 2 \\
C_{N 1}=C_{s 1}+K_{d}\left[1-\left(1+4 C_{s 1} / K_{d}\right)^{1 / 2}\right] / 2
\end{gathered}
$$

The apparent partition coefficient of the acid $\left(K_{s}\right)$ calculated as

$$
K_{s}=\left(K_{H} c_{H 0}+K_{N} c_{N 0}\right) / c_{s 0}
$$

is a function of the acid concentration, even if $K_{H}$ and $K_{N}$ are constant values.

The asymptotic solution of eqs. (10a) and (10b) with conditions (11a) and (11b) in respect to the concentration of acid protons $\left[c_{H}(t)\right]$ and nondissociated molecules $\left[c_{N}(t)\right]$ in compartment B (initially filled with water: see Methods above) is given by

$$
\begin{aligned}
& c_{H}=\left(A_{B} / V_{B}\right)\left(D_{H} K_{H} c_{H 0} / l\right)\left(t-l^{2} / 6 D_{H}\right) \\
& c_{N}=\left(A_{B} / V_{B}\right)\left(D_{N} K_{N} c_{N 0} / l\right)\left(t-l^{2} / 6 D_{N}\right)
\end{aligned}
$$

after the steady state is established $(t \rightarrow \infty) . A_{B}$ and $V_{B}$ are the effective area of the membrane and the volume of compartment $B$, respectively $\left(A_{B}=1.54 \mathrm{~cm}^{2}\right)$.

The sample data representative of HAc permeability through the PVA membrane are shown in Figure 2, making clear the calculation of transport parameters. When the experimental data (as in Fig. 2) are fitted with straight lines

$$
\begin{aligned}
& c_{H}=k_{J H}\left(t-\Theta_{H}\right) \\
& c_{N}=k_{J N}\left(t-\Theta_{N}\right)
\end{aligned}
$$

the permeability of the acid protons $\left(P_{H}\right.$ $\left.=K_{H} D_{H}\right)$ and the nondissociated molecules $\left(P_{N}\right.$ $\left.=K_{N} D_{N}\right)$ can be derived from the trend line slopes $\left(k_{J H}\right.$ and $\left.k_{J N}\right): P_{H}=k_{J H}\left(V_{B} / A_{B}\right) l / c_{H 0}$; $P_{N}=k_{J N}\left(V_{B} / A_{B}\right) l / c_{N 0}$, whereas diffusion coefficients of these species $\left(D_{H}\right.$ and $\left.D_{N}\right)$ can be determined from the time lags $\Theta: D_{H}=l^{2} / 6 \Theta_{H}$ and $\Theta: D_{N}=l^{2} / 6 \Theta_{N}$. Then, the partition coefficients can be found $\left(K_{H}=P_{H} / D_{H}, K_{N}=P_{N} / D_{N}\right)$, enabling the calculation of the apparent diffusion $\left(D_{s}\right)$ and partition $\left(K_{s}\right)$ coefficients of the acid [see eqs. (9) and (14), respectively, as these coefficients vary with the acid concentration].

The diffusion coefficients should be measured at different temperatures representative of the service conditions and the conditions of acceler-
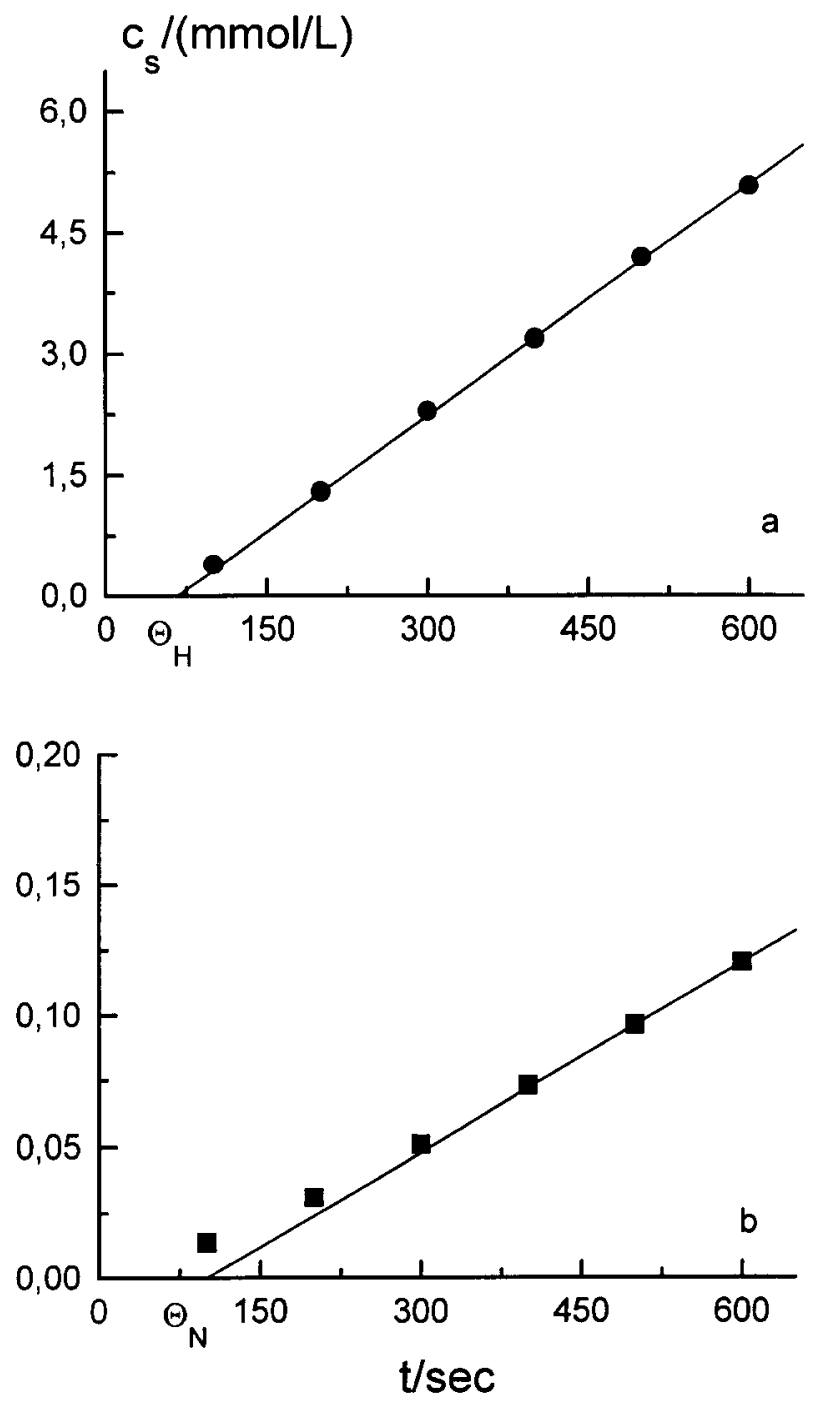

Figure 2 Accumulation of (a) HAc protons and (b) nondissociated molecules in Compartment B of permeability cell due to permeation through PVA membrane. $c_{s 0}=0.1 M$.

ated tests recommended for SMC composites $\left(70^{\circ} \mathrm{C}\right){ }^{5-7}$ When the water and acid diffusion coefficients are measured, the rate of hydrolysis and the concentration of hydrolyzable groups remain the only parameters unknown in eqs. (1) and (2). They can be computed on the basis of the best fitting of the experimental curves of the combined water sorption in and acid release from a material, using model eqs. (1)-(4) with the boundary conditions relative to the diffusion in a film of thickness $l$ :

$$
C_{w}(x, 0)=0 ; C_{s}(x, 0)=0 ; \quad x \neq 0
$$


Table I Diffusion and Partition Coefficients of HAc in PVAc at $20^{\circ} \mathrm{C}$

\begin{tabular}{lcccc}
\hline \multicolumn{1}{c}{$c_{s}(M)$} & $D_{H}\left(10^{-12} \mathrm{~m}^{2} \mathrm{~s}^{-1}\right)$ & $D_{u}\left(10^{-12} \mathrm{~m}^{2} \mathrm{~s}^{-1}\right)$ & $K_{H}\left(\mathrm{~L} / \mathrm{dm}^{3}\right)$ & $K_{N}\left(\mathrm{~L} / \mathrm{dm}^{3}\right)$ \\
\hline 0.1 & 0.23 & 0.18 & 0.43 & 0.009 \\
0.3 & 0.37 & 0.21 & 0.35 & 0.008 \\
0.5 & 0.28 & 0.21 & 0.46 & 0.013 \\
0.8 & 0.31 & 0.22 & 0.40 & 0.016 \\
1 & 0.33 & 0.20 & 0.44 & 0.014 \\
Average value & $0.3 \pm 0.07$ & $0.20 \pm 0.02$ & $0.41 \pm 0.06$ & $0.012 \pm 0.004$ \\
\hline
\end{tabular}

$$
\begin{aligned}
\partial C_{w}(1 / 2, t) / \partial x=0 ; & \partial C_{s}(1 / 2, t) / \partial x=0 ; \\
C_{w}(0, t)=C_{w \infty} ; & C_{s}(0, t)=0 \quad t \neq 0
\end{aligned}
$$

\section{RESULTS AND DISCUSSION}

\section{Permeability of Acetic Acid Through Polymeric Films}

HAc permeability through PVAc, PVA, UPE, and UPE/PVAc membranes (equilibrated with water prior to the permeability experiments as described above) was studied comprehensively at $20^{\circ} \mathrm{C}$, showing no anomalous processes accompanying diffusion. The diffusion coefficients of neither the protons $\left(D_{H}\right)$ nor the nondissociated molecules $\left(D_{N}\right)$ depended on the concentrations of the ions $\left(C_{H}\right)$ or the molecules $\left(C_{N}\right)$, respectively, in the experimental concentration range $(0.1-1 M)$ if we neglect the experimental error.

The results reported in Tables I-IV enabled calculations of the apparent HAc diffusion coefficients $\left(D_{s}\right)$ as they vary with the acid concentration due to acid dissociation [using eq. (9)]. The partition coefficients of the acid protons and the nondissociated molecules, which are also shown in Tables I-IV, can be used for the calculation of the acid partition coefficient $\left(K_{s}\right)$ characterizing HAc solubility in all materials as it varies with the acid concentration. The temperature depen- dence of the HAc partition and the diffusion coefficients follow Arrhenius thermodynamics $[K$ $=K_{\infty} \exp \left(-E_{a} / R T, D=D_{\infty} \exp \left(-E_{a} / R T\right)\right]$ in all materials investigated, as shown for the diffusion coefficients of the protons in Figure 3.

The activation energies of the diffusion and solubility of the protons $\left(E_{\mathrm{ad} H}, E_{\mathrm{ak} H}\right.$, respectively) and the nondissociated acid molecules $\left(E_{\mathrm{ad} N}, E_{\mathrm{ak} N}\right)$ are shown in Table V. The main finding, which is obviously in agreement with the hydrophilic character of the materials, is that the diffusivity of HAc in PVA [refer to the right $Y$-axis in Fig. 3(a)] is three orders of magnitude higher than in the others [refer to the left $Y$-axis in Fig. 3(a)]. Therefore, once HAc releases out the PVAc/ PVA blend or hydrolyzable PVAc, the diffusion in PVA cannot limit the rate of release.

\section{Water Aging of UPE-PVAc Blend}

Figure 4 shows the water-sorption behavior at $70^{\circ} \mathrm{C}$ in slices prepared from the UPE-PVAc blend as described above (see Methods). The material exhibits a convex-shaped kinetic curve with an inflection point (acceleration of sorption) at $\tau$ $=t^{0.5} / l \approx 5.5 \times 10^{5} \mathrm{~s}^{0.5} \mathrm{~m}^{-1}$ [curve 1 in Fig. 4(a)], corresponding to about 3 days of sorption. The inflection point occurs at a relatively high $C_{\mathrm{wt}} / C_{w 00}$ value $\left(C_{\mathrm{wt}} / C_{w 00}=0.85\right)$, which indicates the occurrence of both hydrolysis and hydr-

Table II Diffusion and Partition Coefficients of HAc in PVA at $20^{\circ} \mathrm{C}$

\begin{tabular}{lcccc}
\hline \multicolumn{1}{c}{$c_{s}(M)$} & $D_{H}\left(10^{-9} \mathrm{~m}^{2} \mathrm{~s}^{-1}\right)$ & $D_{u}\left(10^{-9} \mathrm{~m}^{2} \mathrm{~s}^{-1}\right)$ & $K_{H}\left(\mathrm{~L} / \mathrm{dm}^{3}\right)$ & $K_{N}\left(\mathrm{~L} / \mathrm{dm}^{3}\right)$ \\
\hline 0.1 & 0.29 & 0.21 & 1.04 & 0.44 \\
0.3 & 0.27 & 0.16 & 0.96 & 0.59 \\
0.5 & 0.33 & 0.17 & 1.12 & 0.49 \\
0.8 & 0.31 & 0.20 & 1.16 & 0.48 \\
1 & 0.29 & 0.17 & 0.86 & 0.43 \\
Average value & $0.3 \pm 0.03$ & $0.18 \pm 0.03$ & $1.03 \pm 0.17$ & $0.49 \pm 0.1$ \\
\hline
\end{tabular}


Table III Diffusion and Partition Coefficients of HAc in UPE at $20^{\circ} \mathrm{C}$

\begin{tabular}{lcccc}
\hline \multicolumn{1}{c}{$c_{s}(M)$} & $D_{H}\left(10^{-9} \mathrm{~m}^{2} \mathrm{~s}^{-1}\right)$ & $D_{u}\left(10^{-9} \mathrm{~m}^{2} \mathrm{~s}^{-1}\right)$ & $K_{H}\left(\mathrm{~L} / \mathrm{dm}^{3}\right)$ & $K_{N}\left(\mathrm{~L} / \mathrm{dm}^{3}\right)$ \\
\hline 0.1 & 0.46 & 0.30 & 0.26 & 0.007 \\
0.3 & 0.53 & 0.32 & 0.31 & 0.006 \\
0.5 & 0.49 & 0.31 & 0.34 & 0.010 \\
0.8 & 0.53 & 0.31 & 0.31 & 0.012 \\
1 & 0.56 & 0.28 & 0.37 & $0.009 \pm 0.003$ \\
Average value & $0.51 \pm 0.05$ & $0.30 \pm 0.02$ & $0.32 \pm 0.6$ & 0.009 \\
\hline
\end{tabular}

ophilization processes with a predomination of hydrophilization. ${ }^{5-7}$ Although the initial linear parts of the water-sorption curve could be formally described in terms of Fickian diffusion, this would be meaningless due to the hydrolysis of VAc and ester structures at $70^{\circ} \mathrm{C}$ earlier proved ${ }^{6,7}$ for UPE and VAc-containing materials (e.g., composites derived from glass fiber-reinforced polyester resins). The water-diffusion coefficient $\left(D_{w}\right)$ for the UPE/PVAc blend increases from the initial $\left(D_{w 0}\right)$ value of $0.8 \times 10^{-9} \mathrm{~m}^{2} \mathrm{~s}^{-1}$ to a final value 3.75 $\times 10^{-9} \mathrm{~m}^{2} \mathrm{~s}^{-1}$ at equilibrium, showing a remarkable softening of the matrix due to water sorption. The dependence of the water-diffusion coefficient on the water concentration is described by equation

$$
D_{w}=D_{w 0} \exp \left(1.5 \times C_{w} / C_{w 00}\right)
$$

Following earlier findings, ${ }^{2,5-7,12}$ some hydrolysis of ester groups cannot be neglected at $70^{\circ} \mathrm{C}$. Thus, water sorption by the UPE-PVAc composite can be described by a modified eq. (1):

$$
\begin{gathered}
\partial C_{w} / \partial t=(\partial / \partial x)\left(D_{w} \partial C_{w} / \partial x\right)-C_{w}\left(k\left(\left[P_{0}\right]-C_{w}\right)\right. \\
\left.+k_{1}\left(\left[P_{1}\right]-C_{w}\right)\right) \quad 0<x<1
\end{gathered}
$$

where $\left[P_{1}\right]$ is initial concentration of polyester groups subject to hydrolysis; $k_{1}$, the rate constant of hydrolysis of ester groups; and $D_{w}$ follows expression (18).

The kinetics of HAc formation in the hydrolyzable UPE-PVAc matrix and its release from the matrix is still described by the equation system (2) and (4), and two limiting cases can be noted:

1. In the case of fast hydrolysis [in comparison with rate of water $\left(k l^{2} / D_{w}\left(C_{w}=C_{w 0}\right) \gg 1\right]$ and acid diffusion $\left[k l^{2} / D_{s}\left(C_{w}=C_{w 0}\right) \gg 1\right]$, eq. (2) transforms to eq. (4) of Fickian diffusion with the initial condition $C_{s}=\left[P_{0}\right]$. In this case, we should expect linearity of the HAc desorption against the square root of time.

2. Slow hydrolysis $\left[k l^{2} / D_{w}\left(C_{w}=C_{w 0}\right) \ll 1\right]$ and acid diffusion $\left[k l^{2} / D_{s}\left(C_{w}=C_{w 0}\right) \ll 1\right]$ results in a steady-state release with the flux proportional to the rate of hydrolysis:

$$
J_{s}=k C_{w 0}\left[P_{0}\right] l
$$

In the more general case, the steady-state release occurs if the rate of hydrolysis of VAc sequences is equal to the rate of HAc diffusion as described by the equation

$$
\begin{aligned}
&(\partial / \partial x)\left(D_{s} \partial C_{s} / \partial x\right)=-k C_{w}\left(\left[P_{0}\right]-C_{w}\right) \\
& 0<x<1
\end{aligned}
$$

Table IV Diffusion and Partition Coefficients of HAc in UPE/PVAc at $20^{\circ} \mathrm{C}$

\begin{tabular}{lcccc}
\hline \multicolumn{1}{c}{$c_{s}(M)$} & $D_{H}\left(10^{-9} \mathrm{~m}^{2} \mathrm{~s}^{-1}\right)$ & $D_{u}\left(10^{-9} \mathrm{~m}^{2} \mathrm{~s}^{-1}\right)$ & $K_{H}\left(\mathrm{~L} / \mathrm{dm}^{3}\right)$ & $K_{N}\left(\mathrm{~L} / \mathrm{dm}^{3}\right)$ \\
\hline 0.1 & 0.39 & 0.22 & 0.32 & 0.008 \\
0.3 & 0.35 & 0.24 & 0.34 & 0.007 \\
0.5 & 0.36 & 0.22 & 0.37 & 0.006 \\
0.8 & 0.39 & 0.23 & 0.31 & 0.008 \\
1 & 0.40 & 0.21 & 0.37 & $0.008 \pm 0.002$ \\
\hline
\end{tabular}



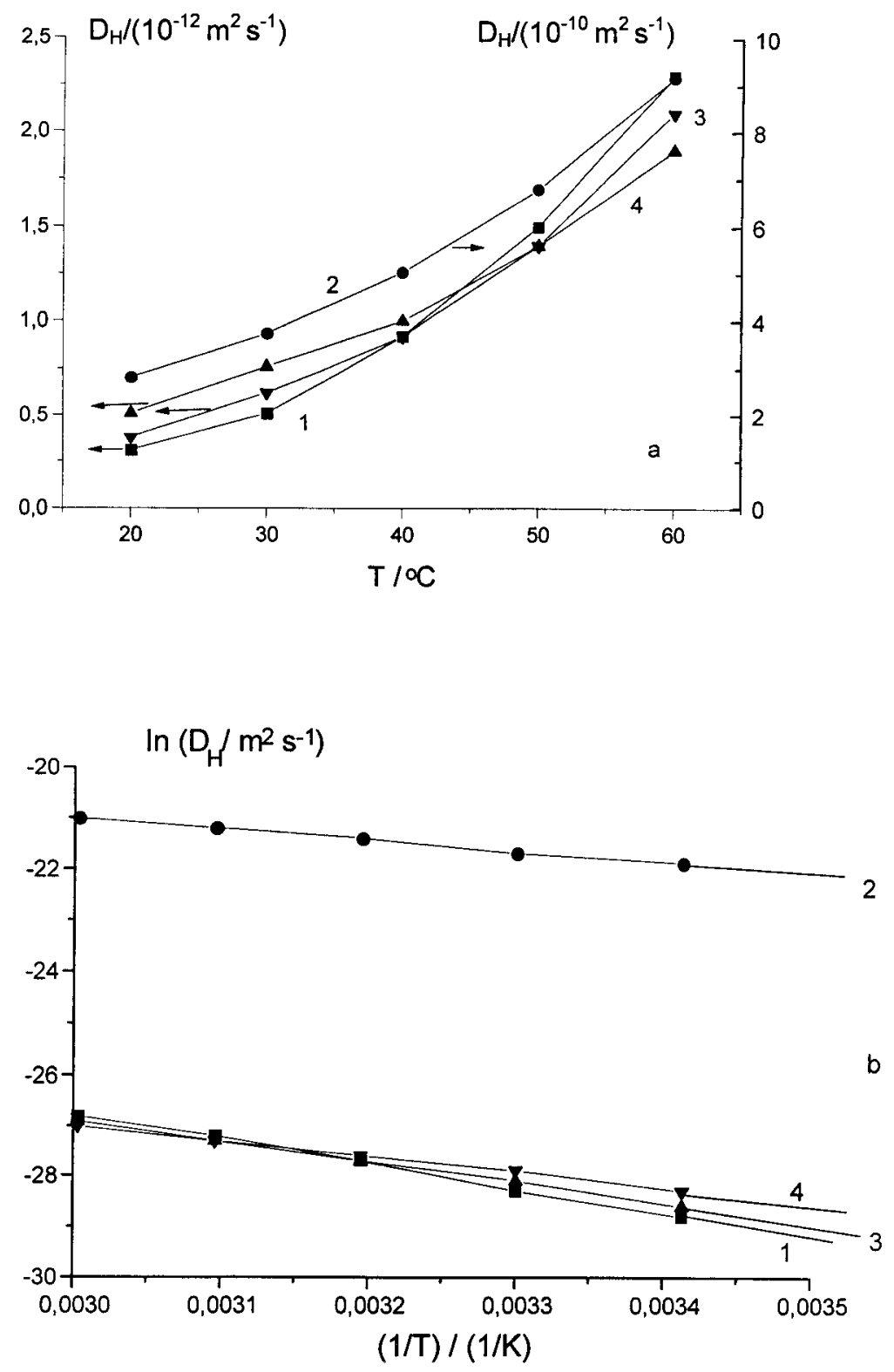

Figure 3 Temperature dependence of the HAc proton diffusion coefficient in (1) PVAc, (2) PVA, (3) UPE, and (4) UPE/PVAc.

A partially constant rate of HAc release was indeed observed experimentally, as shown in Figure 4(b) (curve 2 plotted against time). The value of the rate constant of VAc hydrolysis (as well as of the initial concentration of VAc hydrolyzable groups) was obtained by fitting the water-sorp-

Table V Activation Energies of HAc Diffusion and Solubility in Glassy Polymers

\begin{tabular}{lcccc}
\hline Polymer & $E_{\mathrm{ad} H}(\mathrm{~kJ} / \mathrm{mol})$ & $E_{\mathrm{ad} H}(\mathrm{~kJ} / \mathrm{mol})$ & $E_{\mathrm{ad} N}(\mathrm{~kJ} / \mathrm{mol})$ & $E_{\mathrm{ak} N}(\mathrm{~kJ} / \mathrm{mol})$ \\
\hline PVAc & 20.0 & 14.1 & 16.7 & 46.0 \\
PVA & 9.0 & 3.7 & 8.2 & 10.2 \\
UPE & 12.6 & 8.2 & 10.3 & 20.1 \\
UPE/PVAc & 16.4 & 10.3 & 13.8 & 23.6 \\
\hline
\end{tabular}



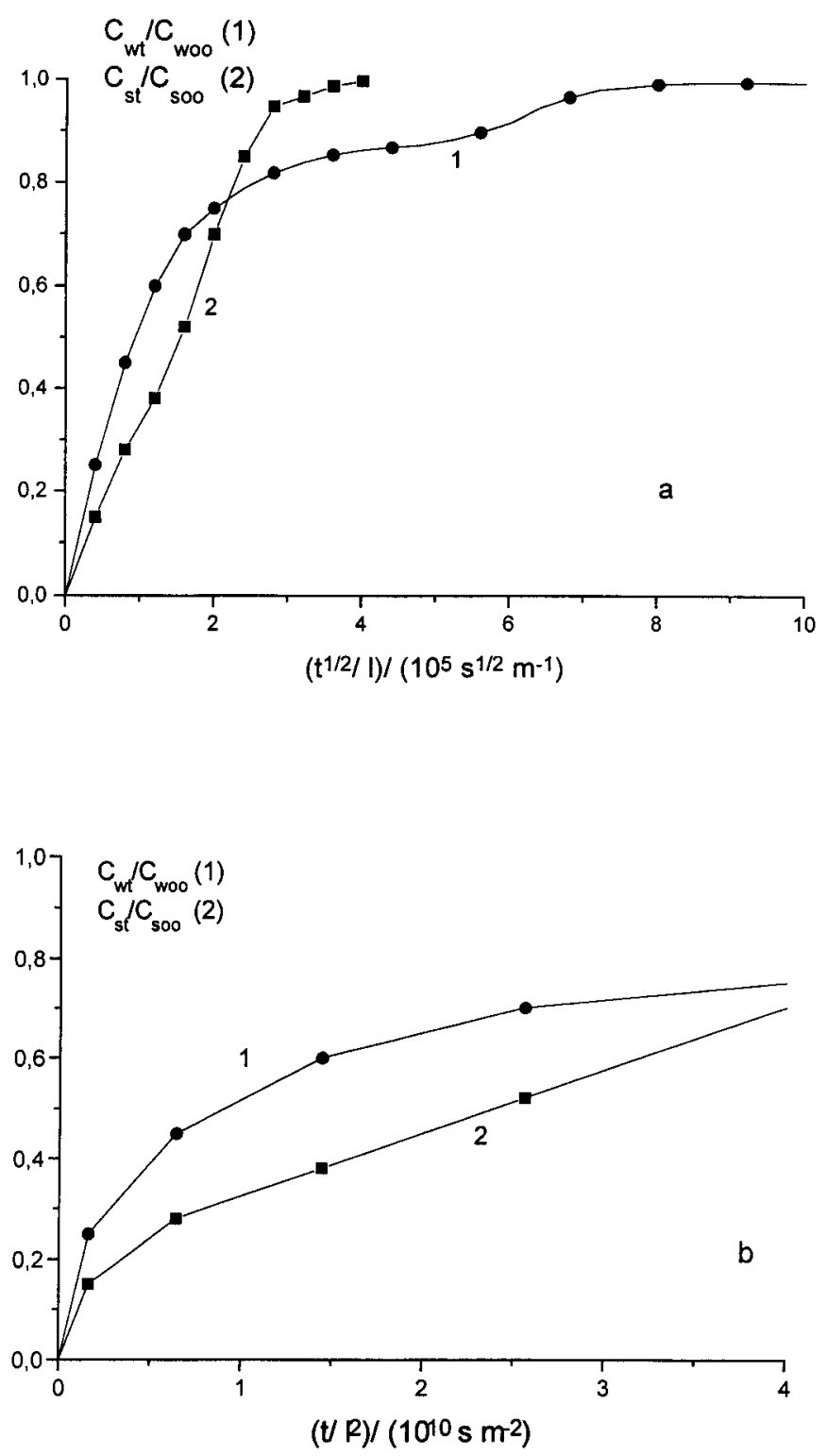

Figure 4 Kinetics of (1) water sorption in and (2) HAc release from UPE/PVAc films at $70^{\circ} \mathrm{C}$.

tion and the acid-release curves with eqs. (2) and (4) and the boundary conditions (16) and (17). These values (shown in Table VI) are similar to those obtained by numerical optimization of the parameters describing water sorption by PVAccontaining composites derived from UPE. ${ }^{10}$ By providing an opportunity of quantitative characterization of water aging of PVAc-containing ma-

Table VI Fitting of the Water Sorption and Release Kinetics with Eqs. (4) and (5)

\begin{tabular}{lc} 
Initial concentration of hydrolyzable groups & {$\left[P_{0}\right]=9.2$} \\
{$\left[P_{0}\right]\left(10^{-4} \mathrm{~kg} \mathrm{~mol} \mathrm{~kg}{ }^{-1}\right)$} & {$\left[P_{0}\right] / C_{w 00}=0.26$} \\
Rate constant of hydrolysis & $k=3.5$ \\
$k\left(10^{-6} \mathrm{~s}^{-1}\right)$ & $k\left[P_{0}\right] l^{2} / D_{w 0}=0.35$ \\
\hline
\end{tabular}


terials, the results of current work enable the prediction of properties of a wide number of engineering polymers and composites.

\section{REFERENCES}

1. Zaikov, G. E.; Iordansky, A. L.; Markin, V. S. Diffusion of Electrolytes in Polymers; VSP: Utrecht, The Netherlands, 1988.

2. Springer, G. S. In Environmental Effects on Composite Materials; Springer, G. S., Ed.; Technomic: Lancaster, PA, 1988; Vol. 3, p 1.

3. Atkins, K. E. Hanser Gardner Publ 1993, 49.

4. Kinkelar, M.; Lee, L. J Appl Polym Sci 1992, 45, 37.

5. Camino, G.; Luda, M. P.; Polishchuk, A. Ya.; Revellino, M. Composites 1996, 18, 40.
6. Camino, G.; Polishchuk, A. Ya.; Luda, M. P.; Revellino, M.; Blancon, R.; Merle, G.; Martinez-Vega, J. J. Comp Sci Tech 1997, 57, 1469.

7. Camino, G.; Polishchuk, A. Ya.; Luda, M. P.; Revellino, M.; Blancon, R.; Martinez-Vega, J. J. Polym Degrad Stab 1998, 61, 53.

8. Polishchuk, A. Ya.; Zaikov, G. E. Multicomponent Transport in Polymer Systems for Controlled Release; Polymer Science and Engineering Monographs; Gordon and Breach; New York, 1997.

9. Valente, A. J. M.; Polishchuk, A. Ya.; Lobo, V. M. M.; Burrows, H. Langmuir 2000, 16, 6475.

10. Crank, J. The Mathematics of Diffusion, 2nd ed.; Clarendon: Oxford, 1975.

11. Tokita, M. Jpn J Appl Phys 1995, 34, 2418.

12. Camino, G.; Polishchuk, A. Ya.; Luda, M. P.; Revellino, M. Polym Comp 2000, 21, 821. 